\title{
A CATEGORIA POBREZA NA FORMULAÇÃO DAS POLÍTICAS SOCIAIS NO CONTEXTO LATINO AMERICANO
}

MONNY MIRELLE DE CARVALHO ARAUJO'; MARIA ADRIANA DA SILVA TORRES ${ }^{2}$

${ }^{1}$ Estudante em Serviço Social pela Faculdade Raimundo Marinho. CV: http://lattes.cnpq.br/0674795278905810

${ }^{2}$ UFAL. Doutorado em Sociologia pela UFPE. CV: http://lattes.cnpq.br/6185915593010959

\section{Artigo submetido em Junho/2016 e aceito em Julho/2016}

\section{RESUMO}

O presente artigo faz uma análise sobre a configuração da Política Social no cenário sóciohistórico da América Latina, sob a perspectiva da economia dependente na dinâmica do capitalismo mundial, e seu desenrolar a partir da crise de 1970 até os anos 1990, quando atribui à focalização na pobreza as suas formulações basilares como resposta ao aumento do desemprego e da população pobre do continente, consequência dos impactos causados pela globalização e pelas transformações societárias do capitalismo contemporâneo. Esta proposta parte da totalidade das relações sociais de produção capitalista, analisadas à luz da teoria social crítica marxista, apropriando-se das teorias genuínas da América Latina para um conhecimento aprofundado sobre a organização desta realidade.

PALAVRAS-CHAVE: América Latina. Dependência. Neoliberalismo. Pobreza. Política Social.

\section{ABSTRACT}

This current article makes an analysis on the configuration of Social Policy in the social historical scenario in Latin America, under the perspective of the economical dependency on the dynamics of world's capitalism, and its development from the 1970 crisis until the 1990s, when I focused in poverty to its basic formulations in response to the rising unemployment and raise of the poor over the ontinent's population, as a result on the impacts of globalization and corporate transformations of contemporary capitalism. This proposal is from the totality of social relations on capitalist production analyzed in the critical light on the social theory of Karl Marx, appropriating of theories in Latin America for an in-depth knowledge over the organization of this reality.

Keywords: Latin America. Dependency. Neoliberalism. Poverty. Social Policy. 


\section{INTRODUÇÃO}

O presente artigo faz uma análise sobre a configuração assumida pela Política Social no contexto da América Latina, inserida sob a insígnia da dependência na dinâmica do capitalismo mundial. Tal análise se faz a partir da perspectiva marxista da dialética da dependência na qual, segundo as leis gerais da produção capitalista, as condições socioeconômicas desse continente estão ajustadas a esta forma de sociabilidade, caracterizando uma dinâmica em que ocorre de forma correlacionada o desenvolvimento de alguns estados nacionais em detrimento de outros, bem como revela a possibilidade de numa mesma realidade haver o desenvolvimento das forças de produção capitalista acompanhadas do aprofundamento das mazelas dessa sociedade.

Nessa orientação, analisamos os fundamentos ontológicos da Política Social latinoamericana e a maneira como ela se desenvolve para atender aos interesses do capital internacional a partir da crise da década de 1970 até os anos 1990, quando a partir da lógica neoliberal atribui às suas formulações basilares a focalização na pobreza em detrimento dos direitos sociais como resposta ao aumento da pobreza e do desemprego estrutural resultantes das profundas transformações causadas pela globalização e pelas mudanças no modo de produção capitalista.

Como direcionamento dessa pesquisa foi utilizado o método marxiano que, desce do concreto (no plano da objetividade) ao abstrato (no nível da subjetividade) e volta para o concreto (espaço da objetividade), com vistas à apreensão efetiva da realidade. Tal método foi escolhido por se caracterizar pela pesquisa profunda, identificando as contradições e conexões existentes. Entretanto, além de apresentar as contradições e conexões faz-se necessário apresentar os seus fundamentos, mostrando que há um ponto de partida dos próprios fenômenos na sociedade, ao mesmo tempo em que há aspectos antagônicos e idênticos.

Portanto, para nossas análises coube um método que ultrapassasse a reflexão acrítica ou vaga dos fenômenos sociais e estabelecesse mediação com o real, analisando os fundamentos ontológicos da Política Social e sua configuração no contexto socioeconômico da América Latina, reconhecendo a relação contraditória entre este continente e os países do capitalismo central, sem se limitar a uma pesquisa de cunho unicamente quantitativo ou qualitativo, mas conformando um estudo quanti-qualitativo que possui características de ambas as pesquisas.

Nesse âmbito, salientamos que o estudo bibliográfico se realizou nas contribuições teóricas marxistas, principalmente nas produções latino-americanas que buscam identificar o caráter da formação socioeconômica deste continente, a sua posição no contexto do capitalismo mundial e a configuração das Políticas Sociais dentro de uma economia dependente, segundo os autores da dialética da dependência.

A partir dos anos 1970, em resposta à crise global $^{1}$., o Estado passa por uma reconfiguração no seu papel, atingindo de forma direta e grave as Políticas Sociais, o que afeta diretamente as condições de vida da classe trabalhadora em todo o globo.

\footnotetext{
1 Segundo Rocha et al (2010), o cenário pós crise estrutural vem sendo marcado ao longo dos anos pelo intensivo investimento de bilhões de reais nos setores privados em prol da salvação do sistema, estratégia que
}

Dialektiké, v. 1, 2016. p. 03-17 
Conforme apontam Rocha et al (2010), as Políticas Sociais são produto próprio da sociedade liberal-burguesa e devem estar relacionadas às modalidades de intervenção do Estado no campo dos conflitos que envolvem a totalidade das relações sociais capitalistas como respostas às reivindicações dos trabalhadores. De caráter contraditório, refuncionalizam-se, simultaneamente, para atender às demandas que se apresentam no cotidiano.

Atuando como mecanismo de aproveitamento do excedente econômico ${ }^{2}$, possuem medidas (benefícios, programas, serviços, projetos e etc.) dedicadas ao enfrentamento da "Questão Social" ${ }^{3}$, sendo formuladas em um espaço institucionalizado de dominação político-ideológica burguesa, atendendo aos interesses do capital em reproduzir-se e controlar a força de trabalho. Nesse quadro, o Estado tem função atuante enquanto mecanismo de intervenção extra-econômico. Para a compreensão sobre o papel do Estado mediante a imediaticidade das expressões da "Questão Social" e dos interesses do capital, Paulo Netto apud Rocha et al. (2010) recorre à fase monopólica do capitalismo no século XIX, momento em que o Estado assume função singular no processo de acumulação capitalista, atuando como guardião das condições externas ao modo de produção, com funções políticas interligadas às suas funções econômicas.

A Política Social do Estado burguês na ordem monopólica é de intervenção contínua, sistemática, estratégica, por meio das quais o Estado procura administrar as expressões da "Questão Social" adequando essa administração aos interesses provenientes da nova metodologia de acumulação do capitalismo, conformando na adesão das categorias e setores inclusos nas suas demandas. Porém, Paulo Netto (1996), pontua que é equivocada a análise que considera a Política Social algo natural e imediato à transição do capitalismo concorrencial para o estágio monopolista, pois os processos de constituição destas e de reconfiguração do papel do Estado são tensionados pelas lutas de classes, de modo que as Políticas Sociais são resultantes extremamente complexas de um contexto em que protagonistas e demandas estão envolvidos por contradições, conflitos, confrontos e objetivos distintos.

Para uma análise concreta sobre as Políticas Sociais é necessário considerar os determinantes que conformaram a sua materialidade: a participação do Estado no processo de acumulação do capital e na dinâmica das lutas de classes, pois para a implementação das Políticas Sociais faz-se necessário que haja um excedente econômico produzido pela classe trabalhadora e apropriado pelo Estado. Rocha et al. (2010) afirmam que o excedente econômico é o ponto importante para a apreensão da Política Social pelo capitalismo dos monopólios, mas pela primeira vez se manifestava como um problema para os chefes das

ganha força nos discursos oriundos da ideologia burguesa que investe contra a reputação dos serviços prestados pela máquina pública, além de romper com os mecanismos que legitimam a execução destes serviços com qualidade. Tais ações desconsideram ao longo das suas formulações e execuções os interesses e necessidades da classe trabalhadora.

'lbid., p. 157.

${ }^{3}$ Carvalho e lamamoto apud Santos (2012) seguem a perspectiva de parte dos autores marxistas que consideram a "Questão Social" enquanto conjunto de expressões do processo pelo qual se formou e desenvolveu a classe operária e de como esta se inseriu no cenário político da sociedade exigindo seu reconhecimento enquanto classe social por parte do Estado e do empresariado. A "Questão Social" é a expressão da contradição entre capital e trabalho, exigindo intervenções que vão para além da caridade e da repressão.

Dialektiké, v. 1, 2016. p. 03-17 
empresas monopolistas em razão da incapacidade crônica de absorção do máximo desse excedente econômico, pois as formas clássicas de utilizá-lo tornaram-se incapazes de absorvê-lo produtivamente. Eis o problema: um excedente em constante crescimento sem aproveitamento produtivo.

A partir disso, surgem novas formas de aproveitamento focadas em abreviar as crises capitalistas, dentre elas são estas as três primordiais:

a) despesas com publicidade, em campanhas que visam estimular o incremento do consumo, através da manipulação dos consumidores; $b$ ) gastos com a máquina militar, através da produção e comercialização de armas, manutenção e incremento das estruturas de guerra (internas e externas); c) despesas com a administração civil, na qual há a inclusão de gastos com a manutenção de funcionários públicos, força policial e políticas sociais, tendo 'nesse item, a educação pública, estradas, saúde e higiene, conservação e recreação, comércio e habitação, política e bombeiros, tribunais e prisões, Legislativos e Executivos'. (BARAN e SWEEZY apud Rocha et al., 2010, p.160, grifo nosso).

Portanto, é do problema em direcionar o excedente econômico de forma produtiva que surgem diferenciadas alternativas para o seu aproveitamento, muitas relacionadas ao estímulo ao consumo, algumas direcionadas à proteção dos monopólios, burocratizando a vida. Além disso, também são direcionadas às medidas de intervenção da administração pública na esfera da reprodução social, dentre essas medidas está a Política Social.

Todo esse processo ocorrido na fase monopólica exige a especificidade latinoamericana, em que o Estado ${ }^{4}$ nesse continente também foi moldado de acordo com essa nova lógica de acumulação capitalista, contudo as contradições presentes nessa conjuntura têm outras proporções: à medida que o problema do excedente é de outra ordem, consequentemente a Política Social que se desenvolve nesse continente também tem outras proporções e suas particularidades históricas.

\section{A ESPECIFICADIDADE LATINO-AMERICANA: PROCESSO DE FORMAÇÃO SÓCIO- ECONÔMICA E O ESTADO LATINO AMERICANO}

Segundo Marini (2000), o Estado nos países latino-americanos possui um determinante papel na conformação sócio-política e econômica do continente. No período da vigência do estatuto colonial coube ao estado na América Latina apropriar-se do excedente produzido e enviá-lo à metrópole. Para atender a essa empreitada, os trabalhadores foram submetidos à escravidão ou semiescravidão, sob visível e sangrenta repressão às lutas, revoltas e movimentos sociais.

${ }^{4}$ Trata-se da formação do perfil específico do Estado no contexto latino-americano.

Dialektiké, v. 1, 2016. p. 03-17 
Com o fim do regime, os estados coloniais passaram à condição de estados independentes, com frágeis burguesias locais que buscavam manter o controle sobre a produção preparando o estado para ser o eixo fundamental de base para a superexploração dos povos latino-americanos. O papel do Estado nesse período é o de investir em infraestrutura para preparar a estrutura social e econômica para o movimento global do capital, ampliando assim a escala de mercado e a transferência do excedente econômico latino-americano para os países centrais.

Nesse contexto entra a implantação das ditaduras militares, já que o estado ditatorial surge com a tarefa de promover os ajustes estruturais necessários para adequar o continente à ordem monopólica e reprimir toda e qualquer possível organização da classe trabalhadora. Portanto, o estado latino-americano se modificou de maneira a se tornar instrumento de dominação externa dentro da América Latina, tornando-se a expressão máxima do poder econômico.

Cueva apud Rocha et al (2010) afirma que essa característica peculiar do Estado latino-americano é também consequência da maneira como esse continente foi inserido na dinâmica do capitalismo mundial, sendo moldado a essa dinâmica com determinações que atendiam aos interesses do imperialismo, dentre elas a de transferir-lhe as potências e o excedente econômico.

O excedente da América Latina, fruto da mais valia ${ }^{5}$, é apropriado pelo capital privado nacional, pelo capital privado internacional e pelo Estado por meio de impostos diretos sobre todos os tipos de rendas. Isso, resultante da sua condição dependente no momento histórico mercantilista do capitalismo mundial que direcionava os excedentes locais para os grandes centros urbanos do capitalismo. Dessa forma,

\begin{abstract}
Os senhores feudais europeus obtinham um excedente econômico da população por eles dominada, e o utilizavam, de uma forma ou de outra, em suas próprias regiões, enquanto o objetivo principal dos espanhóis, que recebiam do rei minas, terras e indígenas na América, consistia em subtrair um excedente para transferi-lo para a Europa. Esta observação contribuiu para esclarecer a meta final que teve, desde sua implantação, a economia colonial americana; embora formalmente mostrasse alguns aspectos feudais, atuava a serviço do capitalismo nascente em outras comarcas. No fim das contas, tampouco em nosso tempo a existência dos centros ricos do capitalismo pode explicar-se sem a existência das periferias pobres e submetidas: uns e outras integram o mesmo sistema (FURTADO apud GALEANO, 2010, p.22-23).
\end{abstract}

Em outras palavras, o excedente econômico próprio da América Latina era disputado entre os senhores feudais europeus que o aplicavam em suas propriedades, sejam elas localizadas no próprio continente latino-americano ou na Europa. Além disso, Humboldt apud Galeano (2010, p.23) observa que, "não menos da metade da propriedade de base e

\footnotetext{
${ }^{5}$ Extraída por meio de uma maior exploração da força de trabalho na periferia que, segundo Marini (2000, p.155), isso ocorre devido ao "caráter contraditório da dependência latino-americana que confere uma dinâmica especial no âmbito das relações de produção do conjunto do sistema capitalista de produção".
}

Dialektiké, v. 1, 2016. p. 03-17 
do capital total do México pertencia, segundo seu testemunho, à Igreja, que além disso controlava boa parte das terras restantes mediante hipotecas".

O montante do excedente apropriado pela burguesia é transformado em lucro, em que parte é usufruída pela própria burguesia e outra parte é usada na aquisição de bens para consumo dos próprios capitalistas. Cabe aqui tratar do caráter específico do processo de subdesenvolvimento da América Latina, da sua inserção até a integração ao capitalismo mundial, para compreensão a respeito do papel do Estado nesta conjuntura.

O processo de produção que é estabelecido nos países periféricos ${ }^{6}$ deve ser entendido enquanto uma expressão da dialética do modo de produção capitalista em seu processo de expansão. O que não deve ser interpretado como uma falha no sistema, pois esse processo faz parte da sua dinâmica que subsume todos os elementos da sociedade às regras do capital. Está dado, desse modo, o processo em que os países centrais do capitalismo apropriam-se das potencialidades dos países pobres que constituem o capitalismo periférico ${ }^{7}$ para atender às demandas do imperialismo. Vejamos:

O modo de produção e a estrutura de classes de cada lugar têm sido sucessivamente determinados, de fora, por sua incorporação à engrenagem universal do capitalismo. A cada um dá-se uma função, sempre em benefício do desenvolvimento da metrópole estrangeira do momento, e a cadeia das dependências sucessivas torna-se infinita, tendo muito mais de dois elos, e por certo também incluindo, dentro da América Latina, a opressão dos países pequenos por seus vizinhos maiores e, dentro das fronteiras de cada país, a exploração que as grandes cidades e os portos exercem sobre suas fontes internas de víveres e mão-de-obra (GALEANO, 2010, p.5).

Em outras palavras, o que ocorre é a absorção das potências da América Latina, a ponto de colocá-la às margens das condições de vivências subalternas, violência patrimonial, cultural, racial, constante e legalizada ${ }^{8}$ para o crescimento do capitalismo mundial. Fica claro que, por mais que desenvolvimento e subdesenvolvimento apareçam como processos antagônicos, ambos são constitutivos de uma mesma lógica de acumulação capitalista em escala mundial, ligados pelo seu antagonismo e pela sua complementaridade ${ }^{9}$. Isso é parte das contradições inerentes ao modo de produção capitalista.

A independência dos países latino-americanos acontece sob um dramático perfil histórico, onde as novas sociedades baseadas na escravidão, no latifúndio e na produção de

\footnotetext{
${ }^{6}$ Termo utilizado por Marini (2000) para se refere aos países onde o processo de produção se dá de maneira simplificada, atrasada perante o desenvolvimento do processo de produção dos países centrais.

${ }^{7}$ Termo utilizado por Galeano (2010).

${ }^{8}$ Utilizamos violência patrimonial, cultural, racial de forma legalizada e constante como formas de interpretação dos meios e mecanismos legais utilizados pelos ocidentais para retirada de matéria-prima e apropriação de terras da América Latina.

${ }^{9}$ Trotsky (2000) apontou as limitações na historicidade dos países subdesenvolvidos enquanto consequência da desigualdade dentro do processo de desenvolvimento do capitalismo mundial. Os países periféricos acabavam por ter um desenvolvimento peculiar no seu interior decorrente dos elementos atrasados que possuíam em paralelo com os modernos elementos dos países do capitalismo central.
}

Dialektiké, v. 1, 2016. p. 03-17 
bens primários para o mercado externo, ainda sofriam fortes influências das suas raízes, com uma cultura colonial de exportação passando no século XIX a integrar profundamente o mercado mundial (em função dos interesses ingleses) no período da Revolução Industrial. Os novos países são inseridos no capitalismo mundial sob a condição de economias agroexportadoras de bens primários em troca dos produtos manufaturados ingleses, relações comerciais que renderam aos países periféricos extensas dívidas financeiras com as metrópoles.

De acordo com Marini (2000) são estabelecidas relações comerciais que reatualizam os termos do intercambio ilegal, em que o sistema de trocas é desfavorável, criando relações comerciais que transferem o excedente econômico para os países centrais, sendo garantidas por uma superexploração da força de trabalho nas regiões periféricas, por meio da intensificação dos meios de exploração de valor e da produtividade próprias dos países dependentes. Dessa forma, a América Latina desempenhou funções que extrapolam os requisitos determinados pela acumulação dos países industriais que têm como efeitos severos sobre os povos ${ }^{10}$ latino-americanos: "a intensificação do trabalho, a prolongação da jornada de trabalho e a expropriação de parte do trabalho necessário ao operário para repor sua força de trabalho" (MARINI, 2000, p. 125).

Diante das condições impostas pelo imperialismo, a parte do excedente apropriado pelo Estado cumprirá três finalidades:

Financiar o processo de acumulação a partir de frentes diversas, tais como investimento em estrutura, subvenções financeiras ao capital internacional, isenção ou redução de impostos, manipulação de preços, etc; pagar a dívida externa e seus juros, bem como os empréstimos realizados, dividendos diversos e amortizações, enviando assim parte considerável do excedente diretamente aos países centrais; e, finalmente, sustentar o financiamento de precários mecanismos de proteção social, a segurança pública e demais investimentos na reprodução social internamente (ROCHA et al. 2010, p.165, grifo nosso).

Sob as exigências do imperialismo mundial, as funções atribuídas ao Estado incluem ações que dão base à superexploração da força de trabalho, bem como apropriação do seu excedente direcionando-o aos feitos que viabilizam os projetos que atendem aos interesses do imperialismo. Dessa forma, sobra pouco subsídio e interesse para as políticas públicas, já que todo o acumulado é destinado à preparação das condições estruturais e econômicas de forma que as adequem às exigências do monopólio. Nesse contexto entram os atores sociais e as lutas sociais que se fazem necessários já que a atenção direcionada à proteção social se dá de maneira forçosa, conjuntura característica da formação sócio-histórica da América Latina, marcada por lutas, protestos, insubmissão da classe trabalhadora às condições de superexploração impostas pelo capital nacional em atendimento aos interesses do capital internacional.

\footnotetext{
${ }^{10}$ Cabe referenciar que Rocha et al. (2010) justificam em seu texto que ao utilizarem a categoria analítica povo, referem-se ao conceito marxiano de classe trabalhadora, porém essencialmente latino-americano: camponeses, indígenas, pobres do campo e da cidade.
}

Dialektiké, v. 1, 2016. p. 03-17 
Segundo Pinheiro (1995), a partir da década de 1970 a América Latina sofreu bruscas mudanças no cenário social, como o redirecionamento dos modelos de desenvolvimento, o Estado passa por uma reconfiguração no seu papel operando como um "conjunto de contrarreformas para contornar a crise do capital, que se traduziram num conjunto de medidas e programas de 'austeridade de natureza deflacionista, os chamados ajustes estruturais'” (SILVA, 2009, p.28-29), o que atingirá as Políticas Sociais que, segundo Behring e Boschetti (2011a), são as formas setorializadas e multifacetadas de enfrentamento das expressões da Questão Social.

Essa transformação no papel estatal ocorre em decorrência da crise da década de 1970 que, segundo Mészáros (2002) trata-se de uma crise estrutural do capital por não se limitar à esfera econômica, atingindo todas as dimensões da sociedade. Enquanto que nas crises cíclicas somente os limites relativos do capital são ativados, na crise estrutural são ativados os limites absolutos do capital levando ao encurtamento do tempo entre o enfrentamento dos pressupostos destrutivos desse controle sociometabólico.

Sobre a classe trabalhadora recaíram as consequências da reação burguesa à crise de 1970 , os ajustes neoliberais adotados pelos governos norte-americano e inglês na década de 1980 e anteriormente pelos governos latino-americanos que serviram de laboratório de experimental (SILVA, 2009) ${ }^{11}$.

Sobre os países periféricos recaíram a contenção de gastos com Políticas Sociais e a intensificação da focalização dessas políticas. Behring e Boschetti (2011b) citam que o desemprego marca todo o período de estagnação na década de 1970, atingindo principalmente as mulheres, os jovens e os imigrantes, ao mesmo tempo em que expulsou um quantitativo considerável de homens adultos da parcela de trabalhadores empregados.

De acordo com Adriana Torres (2013), as ditaduras civis e militares instaladas nesse continente preparam o campo para a aceitação e implantação das propostas do neoliberalismo. A autora pontua que o objetivo da política neoliberal era se contrapor ao modelo Keynesiano, substituindo-o por um modelo de Estado mínimo para os direitos sociais e máximo para o capital financeiro e especulativo, o que exigiu uma nova forma de intervenção estatal e reforçou a subordinação do continente.

A retomada econômica que se estabeleceu no período de 1976-79 se expressa positivamente no campo da produção industrial e da acumulação capitalista, porém essa retomada aconteceu de forma frágil e hesitante já que, segundo Behring e Boschetti (2011b), se deu de forma desigual entre países e setores, além de não alcançar os índices da produção industrial de antes da recessão e não absorver o desemprego gerado em 1974-75. O desemprego é acentuado com o surgimento de políticas monetaristas e antikeynesiana que conduzem a um discurso tendencioso, que fortalece a ideia de que a inflação é resultado das políticas de pleno emprego do período do Welfare State.

A década de 1980 se inicia com a consequente recessão, momento em que "a economia capitalista internacional vai atravessar sua segunda grande recessão generalizada após o fim da Segunda Guerra, em 1980-82, desencadeada nos EUA" (BEHRING e

\footnotetext{
11 Segundo a autora, a implantação da política neoliberal ocorreu na década de 1980 nos EUA durante o governo Reagan e na Inglaterra no governo Thatcher. Anteriormente, em 1973, foi implantada de forma experimental no Chile durante a ditadura de Pinochet.
} 
BOSCHETTI, 2011b, p. 153). Essa crise atingiu bruscamente os países semi-industrializados dependentes, com enorme queda dos preços das matérias-primas.

A crise de 1980-82 aprofunda o desemprego estrutural que já ultrapassava os 30 milhões em 1982. Esse período também é marcado pela forte concorrência interimperialista e movimentos no mercado mundial como reação à recessão, a exemplo a industrialização acelerada de alguns países latino-americanos ${ }^{12}$ com a modificação da situação desses países frente ao mercado mundial constituindo, inclusive, alguns capitais financeiros autônomos.

Essa industrialização acelerada pode ser explicada pelo deslocamento de centro de produção das transnacionais para o continente latino-americano em razão dos salários e preços de matéria-prima serem mais baixos, custo da produção diminuída e também pela transferência da poluição. Vejamos,

\begin{abstract}
O mercado interno desses países é reduzido, não constituindo uma via de absorção efetiva da produção. Portanto, coloca-se um limite dessa reestruturação do mercado mundial, que não conseguiu impulsionar uma expansão acelerada da economia capitalista internacional: miséria estrutural desses países e seu restrito mercado interno (BEHRING e BOSCHETTI, 2011b, p.155)
\end{abstract}

Ou seja, os países periféricos não participam da economia capitalista de maneira ativa, entram como economia integrante sem um crescimento significativo, com o aumento da superexploração da força de trabalho local e de formas de trabalho subalternas, abrem mão de grande parte do excedente econômico para o capital internacional e do fortalecimento do parque industrial local, além de acumular grande endividamento com juros exorbitantes resultantes dos grandes empréstimos feitos ao capital financeiro.

Os anos 1980 foram marcados por modificações estruturais na liberação da economia e reforma estatal. Alguns países latino-americanos tiveram como avanço a extensão das Políticas Sociais, base de um processo de redemocratização política como a que ocorreu no Brasil, por exemplo. Todavia o processo de redemocratização que culminou nas constituições democráticas tem distanciamento na universalização das Políticas Sociais, que são realizadas por meio de programas focalizados.

A crise da década de 1980 e o processo de reforma do Estado abriram espaço para o fortalecimento do discurso neoliberal e para a institucionalização dos programas de transferência condicionada nos países latino-americanos sob a orientação dos países centrais.

\title{
3 POLÍTICA SOCIAL X POLÍTICA ECONÔMICA: A FOCALIZAÇÃO NA POBREZA EM DETRIMENTO DOS DIREITOS SOCIAIS
}

\footnotetext{
${ }^{12}$ Quanto aos países latino-americanos que tiveram sua industrialização acelerada, Behring e Boschetti (2011b) citam o México, Brasil e Colômbia, as autoras citam que a Argentina também é incluída nesse grupo por outros autores, mas isso é questionável visto o intenso sucateamento do parque industrial desse país.
}

Dialektiké, v. 1, 2016. p. 03-17 
A partir da década de 1990, "países como Brasil e Bolívia implementam os processos de ajustes, juntando-se ao coro continental da reorientação econômica" 13 . Segundo Silva (2009, p.179), a América Latina é marcada por,

Um processo de desmonte das políticas sociais e de contrarreforma do Estado, que visa atingir direitos legalmente instituídos, ao mesmo tempo em que possibilita ao capital as inversões em novos nichos de investimento. Neste sentido, as políticas sociais além de serem tragicamente diminuídas, passam a ser privatizadas, direta ou indiretamente.

A autora apresenta a relação entre o capital internacional e o processo de privatização das Políticas Sociais Públicas dos países periféricos. Isso é evidenciado ao modo que a política econômica exige a implementação das privatizações no continente, o que levou ao gigantesco endividamento dos Estados Nacionais, já que estes se tornaram os maiores "beneficiários" dos empréstimos do capital financeiro.

Torres (2013) afirma que diversos países do continente iniciaram o desenvolvimento de Programas de Transferência Condicionada, sendo 15 Programas de Transferência Monetária em 14 países latino-americanos. Todos dirigidos à população mais pobre buscando diminuir os impactos da crise econômica. Na atualidade, 18 países da região possuem Programas de Transferência Condicionada. Segundo a autora, o contexto de mundialização do capital impôs aos países periféricos um conjunto de condições para que estes fossem inseridos no modelo de desenvolvimento dos organismos multilaterais. Ao Estado coube a administração da justiça, segurança, manutenção da ordem, privatização, proteção do setor privado e garantia do funcionamento do mercado.

Pinheiro (1995) apresenta o modelo de Política Social vigente e o proposto (um embate entre liberais e desenvolvimentistas) na América Latina, em que ambas as orientações confrontam-se nos seus critérios. Tendendo-se para a focalização em detrimento do princípio da universalização, a população objetivada passa a ser os pobres. Essa focalização pode ser compreendida, segundo Pinheiro (1995, p.25), "como uma forma de focalização eleitoral", uma velha forma de clientelismo assistencialista. Se por um lado a orientação das Políticas Sociais é no sentido compensatório, atuam no amortecimento dos impactos causados pelas políticas de ajuste fiscal, de maneira que preserve o tecido social, ou seja, a governabilidade e a credibilidade junto ao capital financeiro internacional, do outro trata-se de uma ação social focalizada que se assemelha ao assistencialismo eleitoreiro, utilizado pelas elites conservadoras que buscam a reprodução do seu poder.

Segundo Coggiola (2013), as iniciativas de caráter setorial e emergencial focalizadas na ajuda social ressurgem na década de 1990 quando a soma do impacto causado pela globalização com as sequelas da década anterior (década perdida) suscitou um cenário social marcado pelo desemprego e pobreza social generalizados. Analisemos os dados aproximados sobre a realidade do continente nesse período:

Uma população de 530 milhões de habitantes, a América Latina contava com 200 milhões de pobres, e 80 milhões de pessoas padecendo de fome

${ }^{13}$ Pinheiro (1995, p.16).

Dialektiké, v. 1, 2016. p. 03-17 
[...] A pobreza relativa no bloco latino-americano teve piora entre 1987 e 1998, com 0,3\% a mais de sua população vivendo sob a linha de pobreza absoluta [...] Dessa realidade surgiram iniciativas como o Plan Trabajar da Argentina4, o Bonosol da Bolívia (desdobradas, no governo de Evo Morales, com o Bono Juancito Pinto, especificamente dirigido à infância) e os célebres programas brasileiros, que foram adotados por governos do mais diverso signo político. O irmão mais velho é o programa Progresa (atualmente Oportunidades), iniciado pelo governo mexicano de Ernesto Zedillo, em 1998 (que não impediu a derrota eleitoral do PRI, partido de Zedillo, dois anos depois). As origens e modalidades políticas desses programas foram muito diversas em cada país, mas é indubitável que se trata de um fenômeno geral. Esses programas têm sido tidos como responsáveis pela estabilidade dos regimes políticos da região (COGGIOLA, 2013, p.74, grifo do autor).

A essa demanda deu-se resposta através dos programas sociais focalizados em uma lógica neoliberal que atuam a partir de reformas e combate à pobreza, condições necessárias para o ajuste da realidade latino-americana ao capitalismo mundial. Surgem então os programas de transferência de renda com a função de inserir de forma mais ativa no mercado do consumo de bens, serviços e direitos os grupos sociais que não possuem poder aquisitivo para tal participação econômica. Esses programas de transferência de renda promovem a inserção da população mais pobre no processo de circulação de mercadorias, garantindo a reprodução do sistema capitalista.

De acordo com Silva (2009), tais programas transferem renda de forma monetarizada e focalizada. Além disso, os valores são ínfimos e não produzem efeitos verdadeiramente redestributíveis, pois em realidades como a brasileira, a tributação do Estado atinge de forma agressiva a população contribuinte de menor poder aquisitivo. A arrecadação está regularizada predominantemente nos tributos indiretos, sobre produção e consumo, transferindo para os trabalhadores e classes com menor poder aquisitivo $61 \%$ das receitas arrecadas pela União.

São os programas de transferência de renda a contraface das políticas econômicas de ajuste fiscal, em uma conjuntura que, de um lado há a demanda de população pobre em busca de satisfazer as suas necessidades, desde as mais básicas, enquanto de outro lado há os interesses econômicos do capital. Além de trazer prestigio aos governantes são também compatíveis com a política neoliberal de ajuste fiscal. Esses programas que alegam atender as necessidades básicas, na verdade só operam nas condições de sobrevivência desses indivíduos, destituídos de qualquer caráter de direito social.

Segundo Coggiola (2013, p.78), "estes programas requerem, segundo o modelo proposto pelo Banco Interamericano de Desenvolvimento (BIRD), cortes no orçamento social geral, inclusive em matéria de saúde e educação", o que gera a fragmentação das Políticas Sociais públicas gerenciadas e implementadas pelo Estado - cujo público-alvo deve ser os cidadãos de diferentes classes sociais a partir do princípio da universalidade -, sacrificadas em nome das ações que visam amenizar a pobreza e o desemprego, ambos em níveis altíssimos devidos aos impactos que as políticas econômicas com suas taxações elevadas causam à força de trabalho. 
Pinheiro (1995) afirma que os elementos relacionados à implementação e sustentação de políticas econômicas, ajustes fiscais e políticas compensatórias ganham o interesse de mecanismos unilaterais como o Banco Mundial. Segundo as orientações destes mecanismos, as Políticas Sociais devem atuar na compensação de políticas econômicas e nas suas consequências diretas na pobreza e no desemprego da população.

A atenção dada à Política Social não está voltada para os meios, as ofertas de serviços e coberturas. A nova orientação objetiva mais produzir efeitos na vida da população - alvo, já que do ponto de vista econômico, a deterioração e o rompimento do tecido social gera uma imagem negativa sobre os países latino-americanos, o que depende disso a base para possíveis financiamentos.

A liberação desses financiamentos ocorre quando as exportações superam as importações gerando um déficit na balança comercial. Entretanto esse tipo de capital busca expectativas de rentabilidade e qualquer distúrbio no campo social faz com que eles procurem outros mercados mais atraentes. Nessa orientação, o Estado depara-se com a necessidade de direcionar as suas Políticas Sociais para o controle das mazelas sociais, de modo que estas não afetem o ajustamento. $O$ combate à pobreza torna-se a principal linha de intervenção do Estado na vida social.

Disso surgem as mudanças nas Políticas Sociais latino-americanas, como estratégia na operacionalização do Estado e do capitalismo em meio a uma nova crise, atuando no equilíbrio do tecido social ao mesmo tempo em que cria campos eleitorais.

\section{CONSIDERAÇÕES FINAIS}

As nossas análises sobre a América Latina apresentam a relação do desenvolvimento desigual e combinado que ocorre dentro do capitalismo. Nela o continente latino-americano, sob a insígnia da dependência, encontra-se em uma posição periférica dentro das relações do modo de produção capitalista divergindo de análises pseudoconcretas que apresentam a dinâmica do capitalismo mundial sob uma perspectiva cujo desenvolvimento ocorre de numa sequência linear.

Uma realidade peculiar feito a da América Latina demandou um Estado cuja configuração assumida subordina as potências locais ao capitalismo central. Faz parte dessa lógica o desenho de Políticas Sociais que atuem enquanto mecanismos de conformação da realidade socioeconômica do continente aos interesses dos mecanismos unilaterais.

De acordo com Pinheiro (1995), um indicador das mudanças ocorridas nas orientações das Políticas Sociais latino-americanas são os relatórios produzidos pelo Banco Mundial que tratam do desenvolvimento em nível mundial. A partir da década de 1990, esses documentos orientaram os países do capitalismo periférico a focalizar as ações das suas Políticas Sociais em temas como pobreza, saúde e meio-ambiente, não se limitando a ações referentes ao desenvolvimento.

Observa-se que os custos dos ajustes fiscais apresentaram-se muito altos para as classes mais baixas, gerando uma dramática situação econômica, aumentando, progressivamente a pobreza e o desemprego estruturais. Isso condicionou as Políticas Sociais a uma função compensatória: o objetivo final das Políticas Sociais e a manutenção 
das condições econômico-sociais da população latino-americana passa a ser a manutenção da governabilidade, eliminando a pobreza e possibilidades de desestruturação de governos políticos e de todo o sistema criado em torno dele e para ele.

A pobreza no continente latino-americano impôs aos seus governantes a inclusão na agenda de seus países o combate à pobreza estrutural. A saída encontrada foi a formulação de Políticas Sociais para o enfrentamento das expressões mais agudas da "Questão Social". Tais políticas são "constitutivas de '[...] uma mescla sui generis entre medidas do social-liberalismo e do novo desenvolvimentismo"" (TORRES, 2013, p.151, grifo do autor). Essa formulação promoveu políticas neoliberais com recorte econômico-social gestadas em um espaço de dominação da burguesia nacional e do Estado enquanto aliado, sob a tutela do capital internacional, o que garantiu por meio de alianças a dominação imposta pelo imperialismo norte-americano.

A lógica basilar dessas Políticas Sociais é inserir os setores da classe trabalhadora e da população pobre no mundo do capital financeiro por meio de ações que visam transformar o cidadão de direitos em cidadão consumidor, isso em detrimento das Políticas Sociais que visam garantir os direitos dos cidadãos independentes da sua condição econômica como prever o princípio da universalidade. Nessa lógica, insere-se a parcela da classe trabalhadora que se encontra mais pauperizada no mundo do consumo precário de bens e serviços, ao mesmo em que buscam adequar os Estados nacionais à lógica do capital financeiro, já que operam com programas monetários.

Noutra perspectiva, as Políticas Sociais se apresentam enquanto ganho da classe trabalhadora em um campo de disputas de interesses contra a classe burguesa, como apontam Behring e Boschetti (2011), sendo assim complexas e atravessadas por interesses e disputas de classes.

Os programas de transferência condicionada que surgem para amenizar a pobreza no continente possuem particularidades que podem ser monetárias ou não monetárias. 0 público-alvo desses programas é a população pobre, buscando diminuir os impactos causados pela crise econômica e pelo ajuste fiscal.

As Políticas Sociais são revestidas de um caráter compensatório, tornando-se concessão de benefícios e não direitos sociais legais como constituídos na década de 1980 . Os recursos destinados são cada vez mais reduzidos, ficando para os governos uma pequena parte para o enfrentamento - por meio de programas focalizados, de baixo alcance e valores rasos-, da "Questão Social" e "possíveis tensões que culminem em insubordinação da parcela da população que vive nas condições mais precárias" (SILVA, 2009, p.178).

Para Torres (2013), a intervenção do estado neoliberal por meio dos Programas de Transferência Condicionada implica o novo assistencialismo, utilizado desde 1980 para enfrentar a pauperização contemporânea. Trata-se de um segmento de programas sociais inscritos nas Políticas Sociais direcionadas a segmentos específicos da sociedade.

Tais políticas possuem efeitos limitados, com remuneração inferior, que não resolvem os problemas da concentração e transferência de renda, com valores que apenas reproduzem o lugar desses cidadãos na miserabilidade, além do que as necessidades atendidas são as do consumo precário, e os seus beneficiários ficam reféns do próprio governo sem muitas perspectivas de sucesso. O maior favorecido é o capital portador de 
juros que transfere a distribuição desses recursos públicos entre as instituições bancárias, estas por sua vez pagas pelo Estado por cada operação feita.

As informações aqui apresentadas colocam para a pesquisa científica em torno da Política Social, não apenas dados quantitativos ou qualitativos, mas uma análise ontológica sobre os seus fundamentos e seu desenvolvimento e reconfiguração seguindo a lógica capitalista, desmistificando o caráter paternalista, clientelista e uma possível resolução da "Questão Social" que são atribuídos à Política Social, porém, alertamos para as limitações na execução dessa pesquisa seja no quantum ${ }^{14}$ do acervo teórico pesquisado, cientes de que esse objeto de estudo demanda uma maior disposição de tempo de pesquisa, seja no aprofundamento a respeito de outras categorias analíticas ${ }^{15}$ apontadas no texto.

\section{REFERÊNCIAS}

BEHRING, Elaine Rosetti; BOSCHETTI, Ivanete. Política social: fundamentos e história. 9 ed. São Paulo: Cortez, 2011a. 213p.

Política social no capitalismo tardio. 5 ed. - São Paulo: Cortez, 2011b. 199p.

COGGIOLA, O. Programas sociais compensatórios: a experiência brasileira. Revista Praia Vermelha: estudos de política e teoria social, v. 23, n.1, jan/jun. Rio de Janeiro, 2013.

Disponível em: <http://praiavermelha.ess.ufrj.br/wp-

content/uploads/2014/07/Coggiola.pdf>. Acesso em: 20.11.2015.

GALEANO, Eduardo. As veias abertas da América Latina. 2010. Disponível em: <http://copyfight.noblogs.org/gallery/5220/Veias_Abertas_da_Am\%C3\%83\%C2\%A9rica_Lati na(EduardoGaleano).pdf>. Acesso em: 15.06.2015.

MARINI. Ruy Mauro; SADER, Emir (Org.). Dialética da dependência: uma antologia da obra de Ruy Mauro Marini. - Petrópolis: Vozes; Buenos Aires: Clacso, 2000. 295p.

MÉSZÁROS, István. Para além do capital. Tradução de Paulo Cezar Castanheira e Sérgio Lessa. Campinas, São Paulo: Boitempo, 2002.

NETTO, José Paulo. Capitalismo monopolista e serviço social. 2 ed. - São Paulo: Cortez, 1996. 165p.

PAIVA, Beatriz; ROCHA, Mirella; CARRARO, Dilceane. Política social na América Latina: Ensaio de Interpretação a partir Da Teoria Marxista da Dependência. Revista Ser Social, v. 12, n. 26, p. 147-175, jan./jun. Brasília, 2010. Disponível em:

<http://google.com.br/search?site=\&oq=politica+social+américa+latina\%3ạ+ensaio>. Acesso em: 3.11.2015.

\footnotetext{
${ }^{14}$ Quantidade.

${ }^{15}$ São categorias analíticas aquelas consideradas base para se conhecer o objeto de estudo de forma geral por conterem em si as relações sociais fundamentais.
}

Dialektiké, v. 1, 2016. p. 03-17 
PINHEIRO, Vinicius Carvalho. Modelos de desenvolvimento e políticas sociais na América Latina em uma perspectiva histórica. Disponível em:

<http://www.ipea.gov.br/ppp/index.php/PPP/article/viewFile/141/143>. Acesso em: 25.11.2015.

SANTOS, Josiane Soares. Questão social: particularidades no Brasil. 1 ed. - São Paulo: Cortez, 2012. 272p.

SILVA, Gisele Souza da. Capital portador de juros e programas de transferência de renda: monetarização das políticas sociais e contra reforma. Revista Políticas Públicas. São Luís, v. 13, n. 2, p. 173-181, jul./dez. 2009. Disponível

em:<http://www.google.com.br/url?sa=t\&rct=j\&q=\&esrc=s\&source=web\&cd=1\&ved=0CB0 QFjAA\&url=http\%3A\%2F\%2Fwww.revistapoliticaspublicas.ufma.br\%2Fsite\%2Fdownload.php \%3Fid_publicacao\%3D204\&ei=WKAYVcyGO8inNqTIgegN\&usg=AFQjCNG3gEwoZFkxjPyXXeGVz7VeRzYRA\&bvm=bv.89381419,d.eXY>. Acesso em: 15.11.2015.

TORRES, Maria Adriana (Org.). Trabalho, direitos e políticas sociais na América Latina. Maceió: Edufal, 2013.176p.

TROTSKY, León. La teoria de la revolución permanente (COMPILACIÓN). Buenos Aires: CEIP León Trotsky, 2000. 